\title{
O CHÃO SUBLIME DA PROSA: CRÍTICA E ENSAÍSMO EM WILLIAM HAZLITT
}

\author{
Daniel Lago Monteiro
}

"[José Paulo Paes] considerava-se 'um animal pedestre' e não se julgava 'com asas' para a teorização" (Vilma Arêas - PAES, 2008) ${ }^{1}$

\section{APRESENTAÇÃO}

Durante bastante tempo, boa parte do século XX, o nome de William Hazlitt (1778-1830) foi frequentemente lembrado, em seu prejuízo, ao lado do filósofo e poeta Samuel Taylor Coleridge. ${ }^{2}$ Pois enquanto este arrogava para si o estatuto de teórico e difusor dos fundamentos subjetivos da criação literária, acerca da unidade orgânica da imaginação, cujas origens remontam à Crítica do juízo (1790) de Immanuel Kant - além, é claro, de ter escrito alguns dos poemas mais célebres em língua inglesa -, aquele, sem o aporte do pensamento alemão e sem a invocação da musa, foi o crítico prático, impaciente de todo limite e "inquieto [...] como a camurça" [restless [...] as the chamois], ${ }^{3}$ para fazer valer a imagem de Thomas De Quincey (1973, p. 372) a seu respeito. O mesmo incansável vaguear da mente de Hazlitt foi recentemente ressaltado por Harold Bloom (2005),

\footnotetext{
${ }^{1}$ Frase extraída da apresentação de Vilma Arêas ao Armazém literário (PAES, 2008, p. 13). ${ }^{2}$ Ver "Hazlitt, Lamb e Keats" (WELLEK, 1967, pp. 167-191); e "A imaginação: Wordsworth e Coleridge" (WIMSATT; BROOKS, 1971, pp. 461-493). Também é dessa opinião M. H. Abrams. Do autor, ver "Variedades da Teoria Romântica: Shelley, Hazlitt, Keble e outros" (ABRAMS, 2010, pp. 173-210).

${ }^{3}$ Neste trabalho, todas as traduções do inglês são nossas.
} 
para quem esse caráter se explica dentro da extensa tradição do ensaísmo britânico a que Hazlitt pertenceu - tendo Hume e Johnson antes dele; Carlyle, Pater e Wilde depois (para ficarmos somente nos exemplos de Bloom) - e cuja importância nos dias de hoje é a de nos lembrar da insuficiência de teorias e métodos em crítica literária.

Dos grandes autores do romantismo inglês, nenhum outro ganhou a vida e fez fama literária essencialmente pelos seus ensaios como Hazlitt, e isso, vale lembrar, em uma era de ensaístas de peso, como Charles Lamb, Leigh Hunt, Thomas De Quincey, Samuel Taylor Coleridge, entre outros; do mesmo modo, poucos se dedicaram à crítica com a mesma tenacidade. Como notou Lúcia Miguel Pereira (2016, p. 14): "seus ensaios críticos, que abrangem praticamente todos os escritores desde a época de Elizabeth até a sua, contribuíram largamente para o entendimento de Shakespeare, assim como para o movimento romântico na Inglaterra”. Foi também com inigualável profundidade de gosto, ${ }^{4}$ sutileza de raciocínio e riqueza verbal que analisou quadros e peças escultóricas - ele próprio um talentoso pintor de retratos, a despeito do juízo que fazia de si mesmo nesse ofício. ${ }^{5}$ Em Characters of Shakespeare's Plays (1817), sua obra crítica de mais ampla repercussão, Hazlitt contribuiu como nenhum outro autor antes dele - talvez com a exceção de August Schlegel - para uma visão nova do dramaturgo, por oposição à crítica johnsoniana. Se, nos cursos de Coleridge (1987a, p. 162) sobre literatura, Shakespeare frequentemente "desaparece nas selvas do pensamento" e no "oceano da natureza humana", como observou um de seus alunos, cada peça e cada personagem do bardo são descritas e analisadas por Hazlitt com frescor e energia distintas.

Um dos traços da escrita hazlittiana, para o qual frequentemente se chamou a atenção, é o modo como ela combina a leveza e a elasticidade do ensaio moderno com a estrutura fibrosa e robusta da antiga prosa de língua inglesa ${ }^{7}$ - de autores, nas palavras de Hazlitt (1998d, p. 10), "que saborearam da textura daquilo que descreveram", a exemplo de Sir

\footnotetext{
${ }^{4}$ Em uma carta aos irmãos George e Tom Keats, o poeta John Keats (2002, p. 70) diz que, se há três coisas admiráveis na Inglaterra de seu tempo, elas são: “The excursion' [poema de Wordsworth], os quadros de Haydon e a profundidade de gosto de Hazlitt" ["The excursion", Haydon's pictures and Hazlitt's depth of taste].

${ }^{5} \mathrm{O}$ quadro mais bem sucedido do autor é um retrato do amigo e ensaísta Charles Lamb, hoje parte do acervo da National Portrait Gallery, Londres. Para uma análise do quadro, ver Duncan Wu (2008, Plate 9).

6 "[...] disappears in the ocean of human nature"; "in wilds of thoughts".

${ }^{7}$ Ver, sobretudo, a obra de Tom Paulin (1998).
} 
Thomas Browne e Jeremy Taylor. Ninguém expôs com tanta clareza esse propósito quanto o próprio autor (HAZLITT, 1998, p. 192), no prefácio à edição de Table Talk que publicou em Paris, em $1825,{ }^{8}$ na qual incluiu um primeiro volume de The Plain Speaker (última importante coletânea de ensaios reunidos pelo autor): "ocorreu-me combinar, tanto quanto me fosse possível, estes dois estilos: o literário e o conversacional". 9 Adiante, no ensaio de abertura de The Plain Speaker, "On the Prose-Style of Poets", texto chave para a análise que se segue, a urdidura entre esses dois estilos - da qual depende, segundo o autor, a união entre crítica e ensaística - é adensada em torno da metáfora, recorrente no autor, "o chão da prosa" [the ground of prose].

Central para a crítica e ensaística de Hazlitt, como bem observou Tom Paulin (1998, p. vii) - um dos mais renomados poetas britânicos da atualidade -, é o modo como desenvolveu uma poética da prosa, a partir da noção de que a boa escrita em prosa "possui corpo, forma, textura, beleza ou, em termos hazlittianos, momentum". ${ }^{10}$ Em outras palavras, para Hazlitt o ensaio não é um mero veículo de ideias ou um meio específico para fazer valer as expressões de Theodor Adorno (2008) -, por intermédio do qual o escritor mobiliza conceitos trazidos de fora; tampouco as palavras na prosa equivalem sempre a um vidro transparente, atravessável pelo olhar, como quer Jean-Paul Sartre (2013). Antes, para o crítico inglês, há uma opacidade na prosa ensaística e é por uma imersão no solo de uma língua que os conceitos são gerados e cristalizados em imagens.

Neste artigo, a partir da metáfora o chão da prosa e de seu vínculo com uma noção de sublime firmemente aderida à textura do solo e aos acidentes topográficos, falaremos, primeiro, do ensaio enquanto arte da conversação na qual se permite aos interlocutores (escritor e leitor) elevar ou baixar o tom conforme a ocasião; em seguida, da prosa ensaística enquanto forma robusta, áspera, por oposição à leveza e elevação suave da poesia; e, por fim, do trabalho árduo e sublime que a imaginação do crítico ensaísta precisa enfrentar ao unir ideias dessemelhantes em um todo único, cujo paralelo mais próximo é a arte do escultor.

\footnotetext{
${ }^{8}$ Hazlitt se mudou para Paris com a segunda esposa, Isabella, em setembro de 1824 , onde residiu, entre idas e vindas, por dois anos.

9 " $[\ldots]$ it therefore occurred to me as possible to combine the advantages of these two styles, the literary and conversional".

10 “[...] has shape, form, pattern, beauty or, in Hazlitt's terms, momentum".
} 


\section{“PROJETAR-SE DA SUPERFÍCIE": O BAIXO E O ELEVADO NO ESTILO CONVERSACIONAL}

Na época de Hazlitt, havia mais de dois séculos que a escrita de ensaios atravessara o Canal da Mancha e se firmara na pátria adotiva: a Inglaterra. Se os franceses, com Montaigne, descobriram, nos dizeres de Hazlitt (2016, p. 19), aquela "espécie de escrita [...], que consiste em aplicar os talentos e os recursos intelectuais em toda aquela variada gama de assuntos humanos", foi na Inglaterra que o gênero encontrou um solo fértil. "O ensaio", diz Miguel Pereira (2016, p. 5), "não nasceu na Inglaterra, mas nela encontrou sua pátria de adoção, onde melhor floresceu do que em qualquer outro lugar". " Os principais empreendimentos em escrita ensaística de língua inglesa do século XVIII, a exemplo dos ensaios de periódicos, contribuíram enormemente para dar o tom moderno ao gênero e firmar o ensaio como lugar privilegiado para o exercício da crítica. Contudo, segundo observa Hazlitt (1998d, p. 4), em termos estilísticos, muitos desses ensaios ainda se mantinham presos "a uma moldura regular e preconcebida". ${ }^{2}$

Misto de crônica jornalística, retrato dos costumes, reflexão moral e historieta humorística, a tradição do ensaio de periódico, à qual o autor pertenceu da cabeça aos pés, ${ }^{13}$ teve como principal progenitor The Spectator: folhetim diário que circulou na Grã-Bretanha de março de 1711 a dezembro de 1712 e era redigido, em sua grande parte, pelos fundadores Joseph Addison e Richard Steele. Assim como o seu antecessor The Tatler (algo como O Fofoqueiro), The Spectator possuía aquela característica

\footnotetext{
${ }^{11}$ De Hugo Friedrich a Jean Starobinski, Cynthia Ozick a John Jeremiah Sullivan, Gilberto Freyre a Lucia Miguel Pereira, os estudiosos são unânimes: em nenhum outro lugar o ensaio floresceu como na Inglaterra, depois que o título e o estilo dos Ensaios (de Montaigne), por sorte, aprova Starobinski, impuseram-se na pátria adotiva. Nas palavras de Gilberto Freyre (1978, p. 69), ele próprio um ensaísta de mão cheia e leitor agudo da literatura inglesa: "Mais do que qualquer outra grande literatura moderna, a inglesa se destaca pelos seus ensaístas". Ver também o ensaio de Cinthya Ozick (2011): "Retrato do ensaio como corpo de mulher"; e de Jeremiah Sullivan (2015): "Essai, essay, ensaio".

12 "[...] a regular and preconceived mould".

${ }^{13} \mathrm{O}$ melhor estudo sobre a produção jornalística de Hazlitt é o recém-publicado livro de Kevin Gilmartin (2015). Nele o autor situa o estilo, a forma e as estratégias retóricas dos ensaios de Hazlitt dentro do jornalismo radical da época. Nas palavras do autor: o "método crítico flexível [de Hazlitt], que explora paradoxos e contradições e subjuga tanto a esquerda quanto a direita a um escrutínio corrosivo" [Hazlitt developed a flexible critical method that exploited paradox and contradiction, and subjected the left as well as the right to corrosive scrutiny] (p. 15), contribuiu, a seu modo, para a causa dos radicais.
} 
central da forma ensaio inaugurada por Montaigne. Cito Hazlitt (2016, p. 25): "em que o leitor é admitido nos bastidores e se senta com o escritor vestido de camisolão e chinelos"; numa palavra, o ensaio se pretende uma conversa íntima entre leitor e escritor. Porém, ao contrário de The Tatler, obra que contou majoritariamente com a colaboração de Steele, as oscilações de humor e as reflexões soltas e de ocasião, comuns a uma conversa inteligível e agradável, são sacrificadas em favor do propósito pedagógico e do decoro. Addison se mantém à distância, como mero espectador, ${ }^{14}$ e lê as passagens favoritas a seu auditório, diz Hazlitt (1998b, p. 281), não "como o faria a um amigo, apontando algumas passagens favoritas e explicando certas objeções”, mas como um mestre-escola, enredado "em regras pedantes e fórmulas pragmáticas da crítica, que não fazem bem a ninguém".

Em "On the Prose-Style of Poets", Hazlitt (1998d, p. 4, grifos nossos) censura o traço distintivo da prosa ensaística de Addison, o tom didático e em estilo médio:

O seu estilo [de Addison] não era entalhado, tampouco se projetava da superfície. Não há nele nenhuma ênfase maior nesta ou naquela palavra - ele não se arroja ou para de repente, não submerge ou emerge conforme a ocasião. Do começo ao fim, ele é igualmente insípido, fluente e harmonioso e tem antes o efeito de uma recitação estudada do que de uma fala natural. Isso não teria ocorrido [...] tivesse Addison se colocado a debater em seu clube ou a falar em público, pois assim o seu ouvido teria captado as modulações exatas de som provenientes das sensações momentâneas, as quais ele seria capaz de transferir inconscientemente ao papel. ${ }^{15}$

Ora, não estavam os aspectos fluente e harmonioso da prosa de Addison em consonância com o gosto clássico de sua época, para o qual a arte de conversar, conforme lembra Márcio Suzuki (2014), colocava-se

\footnotetext{
${ }^{14}$ Ver artigo de número 1 do The Spectator, no qual Addison se apresenta diante do público com uma breve biografia de sua persona literária: "Thus I live in the World, rather as a Spectator of Mankind, than as one of the Species" [Desse modo, vivo no mundo mais como espectador da espécie humana do que como membro de sua espécie] (ADDISON; STELLE, 1982, p. 199).

15 "His style [...] was not indented, nor did it project from the surface. There was no stress laid on one word more than another - it did not hurry on or stop short, or sink or swell with the occasion: it was throughout equally insipid, flowing, and harmonious, and had the effect of a studied recitation rather than of a natural discourse. This would not have happened [...] had Addison laid himself out to argue at his club, or to speak in public; for then his ear would have caught the necessary modulations of sound arising out of the feeling of the moment, and he would have transferred them unconsciously to paper."
} 
como critério estilístico? Contudo, segundo Hazlitt (1998c, p. 217), em “On the Familiar Style" o polimento excessivo do tom da escrita havia afastado o "verdadeiro idioma de uma língua" de seu "terreno comum". ${ }^{16}$ Em parte, isso se deve à severidade da separação estilística na era augustana ou, em termos hazlittianos, à incapacidade de submergir e emergir conforme a ocasião: "ascender com o elevado, descender com o baixo, regalar-se com o belo e regozijar-se com a deformidade" (HAZLITT, 1998d, p. 8). ${ }^{17}$

Passemos agora a uma análise de como o próprio Addison, um dos principais porta-vozes das belle lettres na Inglaterra, restringiu o tom elevado apenas à escrita em gênero alto: a poesia épica e trágica.

Muitos são os ensaios do The Spectator dedicados ao exame crítico de obras literárias. Seguindo o caminho aberto pela crítica francesa, Addison apoia suas reflexões em três autoridades do mundo clássico: Aristóteles, Horácio e Longino. O primeiro deles descobrira o ajuste que deveria existir, em obras de gênio, entre os sentimentos e os pensamentos com a linguagem e o estilo, sem o qual, argumenta Aristóteles, a verossimilhança (preceito que garante a unidade da obra de arte) ficaria comprometida. No artigo de número 285 , último de uma série de ensaios críticos sobre a poesia épica de John Milton, diz Addison (1966b, p. 349): “em um poema heroico, requer-se da linguagem que ela seja ao mesmo tempo perspícua e sublime"; 18 ou, nas palavras de Aristóteles (1987, p. 222): "clara e sem baixeza”. Por meio de metáforas e de expressões incomuns, eleva-se a linguagem do "achatamento da prosa" [flatness of prose] (ADDISON, 1966b, p. 352), sem, contudo, perder de vista a clareza da linguagem corrente e a separação dos gêneros.

Quanto ao primeiro critério, o da elevação da linguagem, a poesia inglesa foi muitas vezes bem sucedida - a exemplo do Paraíso perdido (1667). Quanto ao segundo critério, o da unidade de estilo, diz Addison (1966a, p. 121): "a tragicomédia, criação do teatro inglês, é a invenção mais monstruosa que jamais adentrara os pensamentos de um poeta”. 19 Em contrapartida, argumenta o crítico, a poesia francesa de autores como

\footnotetext{
16 "[...] the true idiom of the language"; "the level of ordinary".

${ }_{17}$ "[...] rises with the lofty, descends with the mean, luxuriates in beauty, gloats over deformity".

18 "[...] it is requisite that the language of an heroic poem should be both perspicuous and sublime".

19 "[...] the tragi-comedy, which is the product of the English theatre, is one of the most monstrous inventions that ever entered into a poet's thoughts".
} 
Corneille e Racine conseguiu, como os antigos, encontrar o ajuste entre o pensamento e a expressão.

A mesma observância da unidade estilística vale também para a prosa. Se a poesia heroica se eleva do terreno comum, a escrita de ensaios, gênero médio por excelência, deve permanecer firmemente rente a ele. David Hume (2011, p. 158), cuja escrita de ensaio deve muito a Addison, adverte para os perigos das "expressões incomuns" ou demasiado refinadas, quer em tragédias, epístolas ou escritos filosóficos, pois elas "mais desfiguram do que embelezam o discurso". Na prosa, uma das maneiras de dosar a linguagem e polir o estilo se dá pelo afastamento de qualquer traço que nela eleve o tom acima do chão das coisas: como o patético e o sublime.

Hazlitt herdou da tradição ensaística de língua inglesa do século XVIII, de autores aos quais sempre dedicou honrosa menção, ${ }^{20}$ a afinidade entre o ensaio e a arte da conversação. Assim, diz ele (1998d, p. 5): "não vale um só vintém qualquer estilo que não seja apropriado para ser lido em voz alta ou que não seja aparentado à conversa espirituosa". ${ }^{21}$ Contudo, para Hazlitt, há na prosa, ou na conversa espirituosa, uma espécie própria de inflexão e de modulação do tom que beira o poético e na qual o sublime é incorporado.

Obviamente esse tipo de observação pressupõe toda uma reavaliação dos significados de poesia e de sublime - esta, uma das pedras de toque do Romantismo, sobre a qual falaremos em seguida. Mas foi em uma obra anterior à revolução romântica que Hazlitt e, decerto, boa parte do romantismo, encontrou o genuíno estilo coloquial inglês por oposição ao modelo clássico e francês: A vida de Samuel Johnson, de James Boswell.

A vida de Samuel Johnson consiste em um enorme compêndio de anedotas, reflexões soltas e historietas alimentadas, sobretudo, pelas anotações entre as conversas de Johnson e seu biógrafo, Boswell. Essa monumental biografia transita com primor pelas expressões incomuns e familiares, as exibições de engenho e a mais sincera cordialidade. As personagens, em sua maioria, importantes figuras da vida cultural

\footnotetext{
${ }^{20}$ Em "My First Acquaintance with Poets", ensaio em que Hazlitt narra o momento em que travou contato com Coleridge e Wordsworth, o ainda jovem aspirante ao mundo das letras opôs-se ao juízo dos já aclamados poetas quanto ao mérito estilístico de David Hume: "He [Coleridge] even denied the excellence of Hume's style, which I think betrayed a want of taste or candour" [Ele [Coleridge] chegou até mesmo a negar a excelência do estilo de Hume, o que, a meu ver, trai a sua falta de gosto ou de candura] (1998e, p. 101).

${ }_{21}$ " [...] no style is worth a farthing that is not calculated to be read out, or that is not allied to spirited conversation".
} 
londrina da segunda metade do século XVIII, dão vida e dramaticidade à obra, ou, como diz Borges (2006, p. 148), em Cursos de literatura inglesa, "Boswell fez da biografia de Johnson uma obra dramática com diversos personagens". Mas é, sobretudo, na persona de Samuel Johnson, com seu temperamento - nas palavras de Hazlitt (2016, p. 36), "reflexivo, afiado, espirituoso, bem-humorado, cordial e determinado" - que o estilo conversacional de escrita encontrou um solo familiar à língua inglesa.

Acerca de uma controvérsia sobre qual das personagens de Boswell melhor representaria o estilo conversacional inglês, se Burke ou Johnson, Coleridge (19-?, p. 246) assume o partido doúltimo. Pois, embora Burke seja o tipo "universal de conversador" [universal talker], sua fala, "discursiva" e "contínua", agradava a todos, e sempre. Ao passo que as "assertivas ásperas" de Johnson e seu tom epigramático nunca deixavam de produzir um "efeito decisivo" no ouvinte ou leitor. Ainda sobre a comparação entre o estilo conversacional de Burke e Johnson, diz Boswell (2008, p. 1.279), seja lá com quem aquele topasse nas ruas (não importava a classe social, pois Burke sabia tanto subir como baixar), se com ele travasse uma conversa, ela seria agradável e distraída, como se ambos estivessem pensando em voz alta. Após se despedir de Burke, diria a si mesmo: "lá se vai um sujeito extraordinário". 22

A conversa de Johnson, assim legada pelo seu biógrafo, era grosseira, sem elegância ou beleza, e apresenta um estilo desfigurado e irregular, mas em linguagem não menos tersa e mais artisticamente preparada ao gosto dos temperos locais. Na conversa de língua inglesa, diz Hazlitt (1998b, p. 286), conversa entre amigos, "até mesmo a amargura ou a acidez são agradáveis ao paladar". ${ }^{23}$ Em outras palavras, os ingredientes intragáveis do estilo conversacional de Johnson para o gosto clássico constituem, precisamente, aqueles traços que permitiram ao ensaio moderno projetar-se da superfície e distanciar-se do tom médio e didático. ${ }^{24} \mathrm{~A}$ incorporação das oscilações de tonalidade também foi possível graças à redefinição dos significados do termo sublime e à sua vinculação com o prosaico, sobre o qual falaremos na sequência.

\footnotetext{
22 "[...] this is an extraordinary man".

23 "[...] even a little roughness or acidity, may relish to the palate".

${ }^{24}$ Para uma discussão sobre o estilo a um só tempo beligerante e familiar de Johnson e sobre seu impacto nos escritores românticos, ver o capítulo "Proliferating Words, 17621790" (MEE, 2013, pp. 81-133).
} 


\section{A ÁGuiA E A CAMURÇA: O SUBLIME AO RÉS DO CHÃO}

Em "As flores do mal e o sublime", o crítico alemão Erich Auerbach (2007, p. 312), a partir da análise do poema Spleen, de Baudelaire, expõe com a sagacidade e o didatismo habituais a sobreposição que ali se observa dos níveis estilísticos: a seriedade do metro alexandrino e da atmosfera sublime, ambos mesclados a temas e vocábulos que em nada partilham da dignidade que a tradição conferira ao estilo elevado. A partir do Romantismo, tornou-se cada vez mais frequente esse tipo de sobreposição; e Baudelaire, ao "saltar diretamente de sua miséria para o sublime”, contribuiu como poucos para dar ares de seriedade às mais abjetas das condições humanas.

Em certo sentido, a mistura do sublime com o prosaico, do "ouro com o barro" [mingles clay with his gold], na expressão de Hazlitt (1998d, p. 8), é a forma ensaística por definição. Porém, o ensaísta inglês, escrevendo algumas décadas antes da publicação de As flores do mal, tomou o caminho inverso ao do poeta. Como dissemos acima, para a tradição clássica, o ensaio devia permanecer rente à superfície e rejeitar toda espécie de elevação do tom. No entanto, foi no terreno comum e prosaico que Hazlitt lavrou igualmente suas palavras elevadas e baixas. O seu estilo se eleva não por meio de métricas heroicas, mas por uma imersão no solo de sua língua, "repleto de protuberâncias e de excrescências salientes, ásperas, assimétricas e coberto de amoreiras silvestres", ${ }^{25}$ nas palavras do próprio Hazlitt (p. 174). É das entranhas que a linguagem se arroja e se cristaliza; ou seja, da aliança do sublime com o prosaico.

Em fins do século XVII e ao longo do XVIII, o sublime passou a dividir com o belo a atenção da crítica. O poeta e crítico francês Nicolas BoileauDespréaux foi de grande importância para a revitalização do tema, quando publicou uma tradução de Do sublime (1674), obra atribuída ao autor grego do primeiro século da era cristã, Longino. Praticamente ignorado na Idade Média e no Renascimento, esse pequeno texto de retórica sobre as qualidades imanentes ao discurso elevado e seu efeito no auditório encontrou eco na sensibilidade moderna em ascensão e na psicologia empírica que lhe serviu de base, argumenta Weiskel (1994). A partir do Ensaio sobre o entendimento humano de John Locke (1690) e de seu postulado da primazia da experiência sensível para a conformação da

${ }_{25}$ "[...] full of knotty points and jutting excrescences, rough, uneven, overgrown with brambles". 
mente humana, os temas longinianos passaram a ser analisados à luz de suas implicações psicológicas. Assim, a "grandeza de alma”, primeira das fontes do sublime, segundo Longino (1996, p. 54), e que "se sobrepõe a todas as demais", passou a corresponder, antes de mais nada, à exaltação da mente quando a imaginação não encontra obstáculos e segue adiante, segundo Weiskel (1994).

Um ponto de inflexão na extensa bibliografia sobre o sublime no século XVIII foi, sem dúvida, a obra Uma investigação filosófica sobre a origem de nossas ideias do sublime e do belo, de Edmund Burke, publicada em 1757. Segundo observa outro importante estudioso do tema, Samuel Monk (1960), foi por meio da psicologia lockiana e de seu reexame que Burke desemaranhou o sublime do belo, ponto a partir do qual toda reflexão ulterior se apoia. Pois, enquanto o belo corresponderia ao sentimento de prazer decorrente da conformação dos sentidos às representações do mundo exterior, diante do sublime, os sentidos e a imaginação se veem incapazes de formar uma imagem clara e distinta. Na tensão de abarcar o todo, a mente do espectador é lançada ao píncaro da tensão para, em seguida, despencar no vazio representacional.

Sobre esse movimento do sublime, a "Analítica do sublime" de Immanuel Kant (1790) oferece, decerto, uma interpretação mais abrangente do que a de Burke. Com ela, aquilo que ficaria reservado a sentimentos locais eleva-se a princípios a priori. Contudo, em nenhuma obra anterior ao Romantismo o sublime "se alimentou com forças ganhas em baixo", na expressão de Antônio Candido (2006, p. 18), como no texto de Burke e, nesse sentido, o seu sublime psíquico-fisiológico mostra-se mais fecundo para a nossa leitura do que sua contraparte transcendental.

Tomemos como exemplo uma única passagem do texto de Burke (2013, p. 97, grifos nossos), em que o autor explora as diferenças de grau do sentimento de sublime na contemplação dos espaços naturais.

A extensão pode ser em comprimento, em altura ou em profundidade. Dentre essas o comprimento é o que causa uma impressão menor: um terreno uniforme de uma centena de jardas nunca produzirá um efeito semelhante ao de uma torre de cem jardas de altura, ou um rochedo ou montanha dessa altitude. É lícito supor, igualmente, que a altura seja menos importante do que a profundidade e que nos choque mais olhar para um precipício abaixo do que para um objeto de altura equivalente [...]; e os efeitos de uma superfície irregular e acidentada parecem mais fortes do que quando ela é uniforme e polida.

Com essas palavras, Burke inverteu o sinal das grandezas: o maior dos efeitos provém de baixo, do profundo, e não de cima, do elevado. De 
modo semelhante, o estado da mente no sublime, segundo o autor, é uma sensação invertida, marcada pela privação de um sentimento outrora presente, "uma espécie de tranquilidade toldada de horror" (BURKE, 2013, p. 55); numa palavra, um prazer negativo. Seja nos acidentes topográficos ou nos acidentes de alma, o sublime já não corresponde, para Burke, à mera exaltação. Antes, ele provém das oscilações vertiginosas entre o elevado e o baixo.

Quando os jacobinos subverteram o status quo e abriram uma fenda naquilo que Foucault (1966, p. 54) chama de a "superfície única e lisa" da sociedade, essa noção de sublime cunhada pelo jovem Burke passou a valer também para o plano da política. Diante do evento histórico mais sublime de seu tempo, o Burke maduro, paradoxalmente, tornou-se o principal porta-voz de uma visão orgânica e retrógrada das instituições políticas, tal qual expressas em seus escritos e discursos parlamentares, mais notavelmente nas Reflexões sobre a Revolução em França, de 1790. Contudo, e nisso consiste o maior dos paradoxos do sublime burkiano para os autores do Romantismo, Burke, nos dizeres de Novalis (2009, p. 99), “escreveu um livro revolucionário contra a revolução”. Mas fora Hazlitt, “o romântico radical”, nas palavras de Otto Maria Carpeaux (1966, p. 2012), quem melhor se dedicou a inserir o maior de seus adversários políticos no rol dos grandes escritores de prosa ensaística de seu tempo.

O exame da escrita em prosa de Burke ocupa boa parte do segundo momento de "On the Prose-Style of Poets", cujo propósito é o estudo de alguns casos particulares do encontro, em geral pouco afortunado, entre a prosa e a poesia em língua inglesa. Burke, como se sabe, não foi escritor de poesia ou de obras de ficção. Mas, talvez justamente por isso, sua prosa, em contraste com a dos demais autores analisados - Coleridge, Southey, Byron e outros -, é a mais poética. Enquanto a prosa de Byron, diz Hazlitt (1998d, p. 13), “é pesada, laboriosa e grosseira”, Coleridge "está sempre levantando voo, subindo aos céus em um balão, acima do rés do chão da prosa" (p. 12). ${ }^{26}$ Burke, por sua vez, se eleva com e pelo solo prosaico de sua língua (pp. 7-8, grifos nossos):

Sempre me pareceu que o mais perfeito estilo prosaico, o mais poderoso, o mais estonteante e o mais ousado - o qual esteve mais próximo do precipício que separa a poesia da prosa sem, contudo, jamais se desgarrar dele - foi o de Burke. Ele possui a solidez e os efeitos reluzentes do diamante [...]; nunca perde o

26 "[...] heavy, laboured, and coarse"; "is always getting into a balloon, and mounting into the air, above the plain ground of prose". 
objeto de vista; mais ainda, está sempre em contato com ele, do qual obtém a amplificação ou as variações de seu impulso. Pode-se dizer que ao caminhar "sobre a ponta sólida do cabo de uma lança" ele transpõe sorvedouros; ainda assim, há um lugar de descanso e um suporte tangível para os seus pés: ele não está suspenso no nada. O estilo de Burke se diferencia da poesia, assim eu entendo, tal como a camurça da águia. A primeira ascende a quase igual altitude da segunda: toca nas nuvens, olha para o precipício abaixo, é pitoresca e sublime; mas, entrementes, ao invés de plainar sobre o ar, mantém-se firme no despenhadeiro rochoso, escala de maneira abrupta e intrincada e pasta pelos córtices mais rugosos ou colhe as flores mais ternas. O princípio com o qual guiou a sua pena foi a verdade, não a beleza; não o prazer, mas o poder. ${ }^{27}$

Essa passagem está tão carregada de imagens sublimes, sobretudo aquelas que se distinguem do belo, segundo os próprios critérios de Burke, que a presença do adjetivo sublime, ao final dela, torna-se quase indispensável. Porém, há aqui um componente oculto do sublime que provém das profundezas, dos obstáculos e desafios que a camurça, ou o escritor de prosa ensaística, tem de enfrentar. Em outras palavras, a atividade do ensaísta não é menos sublime do que o terreno sobre o qual ele exerce sua arte.

Desde o Romantismo, ou mesmo pouco antes, a partir dos novos sentidos atribuídos à imaginação no processo de criação literária, a questão da poesia passa a estar emaranhada com a questão do poeta. ${ }^{28} \mathrm{E}$ a figura do pássaro, em consonância com o interesse geral do romantismo pelas formas naturais, expressa bem esse entrelaçamento. Assim, temos, por exemplo, a águia de Gray, o rouxinol de Keats ou o albatroz de Baudelaire. Em um ensaio sobre a versatilidade poética, publicado em 1817 no periódico The Examiner, diz Hazlitt (1998a, p. 149) que a poesia:

\footnotetext{
${ }_{27}$ "It has always appeared to me that the most perfect prose-style, the most powerful, the most dazzling, the most daring, that which went the nearest to the verge of poetry, and yet never fell over, was Burke's. It has the solidity and the sparkling effect of the diamond [...]; it never loses sight of the subject; nay, is always in contact with it, and derives its increased or varying impulse from it. It may be said to pass yawning gulfs 'on the unstedfast footing of a spear': still it has an actual resting place and tangible support under it - it is not suspended on nothing. It differs from poetry, as I conceive, like the chamois from the eagle: it climbs to an almost equal height, touches upon a cloud, overlooks a precipice, is picturesque, sublime - but all the while, instead of soaring through the air, it stands upon a rock cliff, clambers up by abrupt and intricate ways, and browzes on the roughest barks, or crops the tender flower. The principle which guides his pen is truth, not beauty - not pleasure, but power."

${ }^{28}$ É bastante conhecida a formulação de Coleridge (1971, p. 173): "what is poetry? is so nearly the same question with, what is a poet?" [o que é a poesia? e quem é o poeta? são quase a mesma questão].
} 
[...] tem a extensão do universo; atravessa o empíreo e olha a natureza abaixo de uma esfera mais alta. Quando toca a terra, perde algo de sua dignidade e uso. Sua força está em suas asas; seu elemento é o ar. De pé, acotovelada na multidão, está sujeita a ser derrubada, pisoteada, desfigurada; pois suas asas são de um brilho deslumbrante, "do tinto do próprio céu", e a menor quantidade de solo sobre elas lhes é desvantajosa. ${ }^{29}$

É com a mesma imagem que o autor abre "On the Prose-Style of Poets". Ao ter de percorrer "os caminhos enlameados" [dirty roads] (HAZLITT, 1998d, p. 6) do chão da prosa, a imaginação do poeta, quando nela aterrissa, não encontra a mesma liberdade e o mesmo esplendor; suas "asas de gigante impedem-no de andar", como magistralmente sintetizou Baudelaire (2012, p. 137) em um verso de clara inspiração hazlittiana. ${ }^{30}$

No excerto acima, sobre o estilo de Burke, as diferenças entre o prosador e o poeta, bem como as imagens da camurça e da águia associadas a essas duas figuras (respectivamente), deslocam o problema da separação nos níveis estilísticos entre prosa e poesia, da necessidade daquela em se manter no nível plano ou médio, para os diferentes tipos de trabalho que a imaginação exerce sobre o seu material.

\section{O PINTOR E O ESCULTOR: A IMAGINAÇÃO DO CRÍTICO E ENSAÍSTA}

O poeta e crítico inglês T. S. Eliot (1932, p. 18), em um ensaio de 1923, intitulado The Function of Criticism, chama a atenção do leitor para o extenso trabalho crítico que, "em seu mais alto grau" [highest kind],

\footnotetext{
29 "[...] has the range of the universe; it traverses the empyreum, and looks down on nature from a higher sphere. When it lights upon the earth, it loses some of its dignity and its uses. Its strength is in the wings; its element in the air. Standing on its feet, jostling with the crowd, it is liable to be overthrown, trampled on, and defaced; for its wings are of a dazzling brightness, 'heaven's own tinct', and the least soil upon them shews to disadvantage."

$3^{30}$ Sem poder afirmar com segurança a influência de Hazlitt sobre Baudelaire, vale, no entanto, recordar que Sainte-Beuve (1949, p. 439), em L. Boerne; Lettres écrites de Paris pendant les annés 1830 et 1831, depois de comparar a natureza da imaginação do senhor Boerne com uma cotovia "que, no crepúsculo do sol, se eleva, em círculo alegre", lembra que a mesma comparação fora antes feita "por um célebre crítico inglês, Hazlitt, aplicada felizmente ao poeta Wordsworth” [“qui, dans le crépuscle du soir, élève, en cercles joyeux, autour de vertes moissons". Cette comparaisoin, "qu’un célèbre critique anglais, Hazlitt, a déja appliquée fort heureusement au poete Wordsworth"]. Dada a enorme influência de Sainte-Beuve na literatura francesa de seu tempo, não nos surpreenderia se Baudelaire, a partir de sua leitura, tivesse travado contato com o ensaio de Hazlitt e a imagem do pássaro-poeta na multidão, tal qual a encontramos no célebre poema "O albatroz".
} 
antecede ou, de quando em quando, é simultâneo ao ato de criação do autor de poesia ou de obras de ficção. Assim, o "escritor criativo" [creative writer], como os nomeia, "peneira, combina, constrói, apaga, corrige e verifica", ${ }^{11}$ tal qual faz o crítico. Debatendo-se com o outro lado da mesma questão, Hazlitt está preocupado em delimitar o tipo de trabalho criativo ou imaginativo envolvido na arte de escrever ensaios críticos. Não é o caso, como se poderia esperar, de adotar a figura do poeta como modelo para a atividade crítica, em especial o poeta moderno, para quem, nas palavras de Hazlitt (1998d, p. 12) sobre Coleridge, por estar o poeta descolado das coisas, como a águia, tudo passa a depender "da riqueza da mente do autor". ${ }^{2}$ Pelo contrário, para extrair a seiva de seu material e entalhar o pensamento na matéria, é preciso ter os membros firmes no chão como a camurça; e as mãos e os olhos igualmente empenhados como o escultor.

Consiste em um argumento nevrálgico de "On the Prose-Style of Poets" o paradoxo de que a escrita em prosa do poeta é, com frequência, a menos poética. Assim diz Hazlitt (1998d, p. 3): "their style halts, totters" [seus estilos se detêm, titubeiam]. Nessa passagem, Tom Paulin (1998) chama a atenção para a recorrência da dental surda / $t$ / como o elemento articulador da sentença e que expressa, nas palavras de Hazlitt (1998d, p. 3), a "falta de firmeza na marcha do estilo" [want of firmness in the march of his style]. Desse modo, a repetição do fonema - para acrescentar algo à análise de Paulin - parece imitar o caminhar desajeitado e titubeante do pássaro quando toca nos materiais factíveis e irregulares do chão da prosa. Poucos são os proveitos que suas patas esguias e frágeis extraem desse material, do qual mais parecem querer se livrar, alçar voo e ganhar os céus. Por contraste, o estilo do legítimo escritor de prosa é firme e tem os "movimentos ligeiros" e as "pausas expressivas" (HAZLITT, 1998d, p. 3) da camurça. ${ }^{33}$

Um elemento importante que distingue as atividades do poeta das do crítico ensaísta consiste nos modos distintos com que a imaginação de ambos dá forma às suas criações. A ligação entre imaginação e criação literária é, como se sabe, um dos traços distintivos das poéticas românticas. Como lembra C. M. Bowra (1949), a imaginação romântica opõe-se às concepções mais recorrentes do termo, legadas pela tradição, que as identificava como um mero antípoda da verdade e da realidade.

\footnotetext{
${ }_{31}$ "[...] sifting, combining, constructing, expunging, correcting, testing”.

32 "[...] riches of the author's mind".

33 “[...] rapid movements"; "expressive pauses".
} 
Antes, a imaginação romântica consiste naquela capacidade da mente de organizar os dados dos sentidos e de produzir sínteses, sem as quais nenhum elo, no espaço e no tempo, seria possível. Os escritos de crítica de Coleridge foram decerto de grande importância para consolidar essa visão organicista de imaginação. Na Biographia literaria, partindo das observações de Kant sobre a imaginação produtiva e a reprodutiva, o autor desenvolveu a importante distinção entre imaginação e fantasia. Enquanto esta consiste no simples rearranjo dos materiais fornecidos pela experiência empírica, aquela é, nas palavras do poeta, em um primeiro momento, "força vital" e agente de toda percepção humana, e, em um segundo, "vontade consciente" que "dissolve, difunde e dissipa, para então recriar (COLERIDGE, 1971, p. 167)”. ${ }^{34}$ A esse segundo momento da imaginação, o autor cunhou um termo próprio, esemplastic (algo como to shape into one), ou, como bem definiu Davi Arrigucci Jr. (2002, p. 21), “modo orgânico de plasmar a matéria múltipla na unidade". Esta, por sua vez, depende de um extenso e difícil trabalho que a mente do poeta exerce sobre sua matéria, a linguagem.

Na primeira conferência de Hazlitt sobre os poetas ingleses (1818), intitulada "Sobre a poesia em geral" - "seu melhor ensaio teórico", segundo Harold Bloom (2005, p. 73) -, é notória a presença do autor da Biographia literaria, como lembra o estudioso M. H. Abrams (2010). "A poesia é a linguagem da imaginação", diz Hazlitt (1998a, p. 165), ou ainda, ela é a "linguagem mais enfática" (p. 167) com a qual a mente humana "dá forma às coisas" (p. 166). ${ }^{35}$ Congênere à crítica coleridgiana, segundo Hazlitt, o ato de combinar, harmonizar e dar forma ao sentimento interno de um autor não ocorre sem um esforço da imaginação. Porém, há, para esse crítico-poeta, segundo observa um de seus maiores estudiosos, David Bromwich (1999, p. 254), uma espécie de "afinidade eletiva" entre as imagens poéticas, o que alivia o esforço do artista: "na poesia”, diz Hazlitt (1998d, p. 8), "uma imagem prazerosa e tocante naturalmente sugere uma outra”. ${ }^{6}$ Além disso, o produto final do ensaísta prosador contraria,

34 "[...] living power"; "conscious will"; "dissolves, diffuses, dissipates, in order to re-create". Para uma discussão, em língua portuguesa, sobre o papel central da imaginação na poesia e na crítica de Coleridge (2005, p. 86), ver a Introdução de Alípio Correia de Franco Neto, "O sonho mau da vida-em-morte".

35 "Poetry is the language of the imagination"; "most emphatical language"; "shape things". A tradução dessa e de outras passagens de "Sobre a poesia em geral" foi cotejada com a de Roberto Acízelo de Souza (2011, pp. 102-109).

36 "[...] in poetry, one pleasing or striking image obviously suggests another". 
em tudo, o padrão da forma orgânica. Seus materiais são preexistentes e compõem, segundo a analogia de Paulin (1998, p. xv), "uma peça de bricolagem". ${ }^{37}$ Implícita a ela está a ideia de que, ao fim e ao cabo, o ensaio em prosa recusa os pressupostos de uma arte separada da vida prática.

O próprio descolamento da linguagem poética em relação ao uso estritamente corriqueiro de uma língua, a partir do emprego regular da métrica e da acentuação musical da palavra - as asas da poesia, segundo a metáfora que o crítico-ensaísta herdou da tradição -, consiste em um modo menos penoso de coalescer uma imagem na outra: "como um pássaro, ele [o poeta] desliza sobre o ar com facilidade para consigo mesmo e deleite dos espectadores" (HAZLITT, 1998d, p. 3)..$^{38}$ Ainda na primeira conferência sobre os poetas ingleses, ele acentua a liberdade da poesia em relação à matéria prosaica:

[...] para tirar do chão a linguagem da imaginação e capacitá-la a estender suas asas por onde possa satisfazer seus próprios impulsos [...], sem ser interrompida, atormentada ou desviada pela rudeza dos obstáculos triviais, bem como pelas discordantes lisuras e rispidezas da prosa, é que foi a poesia inventada (HAZLITT, 1998a, p. 175, grifos nossos). 39

Na arte de escrever ensaios ocorre o contrário. A imaginação do crítico se mantém rente às coisas e é delas que extrai toda força e movimento. $\mathrm{O}$ que não implica, por sua vez, que a imaginação desempenhe no ensaio, o mais terreno [plain] dos gêneros literários, um papel inferior ao da poesia. Antes, Hazlitt salienta as dificuldades, por assim dizer, sublimes ou másculas que a imaginação do prosador tem de enfrentar para incorporar

37 "[...] a piece of bricolage". Vale lembrar, Montaigne (2002, pp. 273-274) associa seus ensaios a quadros grutescos ou remendos: "Examinando o procedimento de um pintor num trabalho que possuo, senti vontade de imitá-lo. Ele escolheu o lugar mais belo e no centro de cada parede para ali instalar um quadro elaborado com todo o seu talento; e o vazio ao redor, encheu-o de grutescos, que são pinturas fantasiosas cuja única graça está na variedade e estranheza. O que são estes também, na verdade, senão grutescos e corpos monstruosos, emendados como membros diversos, sem forma determinada, não tendo ordem, nexo nem proporção além da causalidade?".

38 "[...] cann cleave the air, like birds, with ease to themselves and delight to the beholders". 39 "It is [...] to take the language of the imagination from off the ground, and enable it to spread its wings where it may indulge its own impulses [...] without being stopped, or fretted, or diverted with the abruptness and petty obstacles, and discordant flats and sharps of prose, that poetry was invented". Na tradução de Acízelo de Souza (2002, p. 108), o final desse trecho se lê do seguinte modo: "[...] bem como pelos dissonantes bemóis e sustenidos da prosa”. Embora os termos sharp e flat possuam uma relação com a música, como bem notou o tradutor, optei por preservar as imagens telúricas (lisuras e rispidezas) igualmente caras aos termos, e em conformidade com o interesse geral deste artigo. 
[embody] a sua fantasia na matéria, cujo paralelo mais próximo são as artes escultóricas.

O tema do paralelo entre as artes - resumido na célebre expressão de Horácio (1994, p. 35), ut pictura poesis [a poesia é como a pintura], e que recebeu particular atenção a partir do Renascimento italiano - reaparece em "On the Prose-Style of Poets", une-se à distinção burkiana de belo e sublime e se insere no interesse geral da tradição romântica pelo papel da imaginação no processo criativo. Assim, para Hazlitt, a imaginação do poeta ou do pintor é bela e delicada, como é sublime e robusta a imaginação do ensaio em prosa ou do escultor. Como se nota nesta passagem:

Um estilo prosaico ou simples parece a ele [ao poeta] pobre e chão [...]. É o mesmo que [...] pedir para um pintor esculpir, pela primeira vez, um bloco de mármore - a frieza do bloco o arrefece, a uniformidade da cor o distrai e a requerida precisão das formas o desanima. O mesmo se dá na escrita em prosa: a precisão de composição aqui exigida enfraquece o entusiasmo do poeta e o amputa de seus recursos habituais. Ele está procurando por belezas, quando deveria estar à procura de verdades; toma o prazer como fim, quando este só é comunicável ao aumentar o senso de poder do leitor. O poeta espalha, ad libitum, as cores da fantasia e as ilusões de sua mente ao redor de todo o objeto; o escritor de prosa está compelido a extrair pacientemente os seus materiais do objeto, parte por parte (HAZLITT, 1998d, p. 6)..$^{\circ}$

Gostaria, por fim, de deter-me um pouco nesta última frase. É curioso observar que o verbo (spread) escolhido pelo autor para designar o que há de comum entre as atividades do poeta e do pintor, também designa, no excerto de "Sobre a poesia em geral", citado anteriormente, o afastamento da imaginação do poeta em relação à matéria prosaica. A imaginação poética estende [spread] as suas asas, como o poeta ou o pintor espalha [spread] as cores de sua fantasia. Há aqui uma liberdade e uma distensão mais evidentes quando contrastadas com o tipo de constrangimento que a forma ensaio impõe ao escritor. Este, diz Hazlitt (1998d, pp. 8-9), é "compelido a extrair os seus materiais do objeto". Isso porque, no ensaio

40 "A direct, or simple prose style seems to him (the poet) bald and flat [...]. It is the same thing as a painter's attempt to carve a block a block of marble for the first time - the coldness chills him, the colourless uniformity distracts him, the precision of form demanded disheartens him. So in prose-writing, the severity of composition required damps the enthusiasm, and cuts off the resources of the poet. He is looking for beauty, when he should be seeking for truth; and aims at pleasure, which he can only communicate by increasing the sense of power in the reader. The poet spreads the colours of fancy, the illusions of his own mind, round every object, ad libitum; the prose-writer is compelled to extract his materials patiently and bit by bit." 
crítico, não só o "tema geral" [general subject] e a "imagem singular" [particular image] são dessemelhantes, e até mesmo "incompatíveis entre si” [so far incompatible], mas também as ideias e os conceitos do crítico, que, quando naquele aparecem, sequer são capazes de comunicar [tell] um argumento geral antes de se fundirem "com o objeto representado" [the object representing it] e de serem "incorporados em um todo único" [embodied in one]. ${ }^{41}$ Como um escultor, o bom crítico, escritor de ensaios, rende-se à "lógica da forma" [logic of form], na expressão de Hazlitt (20o8, p. 34), para a qual toda teoria é magra.

O trabalho exaustivo com as imagens, e a força com que o pensamento e as sensações eram incorporados àquelas deram à crítica e à ensaística hazlittiana um caráter singular. Nela podemos identificar um momento decisivo no gênero em prosa; isto é, o rompimento com a antiga separação dos gêneros e estilos, e que equivale, em certo grau, à fratura que a poesia romântica impôs à tradição. Esse propósito foi levado a cabo, dentre outros, a partir de uma inversão do sentido de sublime. Um dos modos pelo qual ela se deu foi com o emprego de imagens que vinculam a língua ao solo e aos acidentes topográficos. Assim, no "Prefácio" às Baladas líricas (1798), William Wordsworth (2007, pp. 129-130) diz ser a sua noção sublime de poesia decorrente do "terreno fértil" de onde brotam a vida e a linguagem rústicas.

Para Hazlitt, como vimos ao longo deste artigo, no chão sublime da prosa ensaística, as ideias e os conceitos não subsistem de modo independente das imagens a elas entalhadas pelo crítico e escritor. Mais uma vez há aqui um paralelo com a atividade poética. O poeta, segundo Coleridge, cria realidades a partir de uma atividade da imaginação que

\footnotetext{
${ }^{41}$ Nota-se, nessas passagens, semelhanças e diferenças com o que diz Theodor Adorno (2008, p. 37), em "O ensaio como forma", sobre o caráter "mais aberto" e "mais fechado" do ensaio. "Mais aberto na medida em que [...] nega qualquer sistemática [...], mais fechado, porque trabalha enfaticamente na forma da exposição. A consciência da não-identidade entre o modo de exposição e a coisa impõe à exposição um esforço sem limites. Apenas nisso o ensaio é semelhante à arte; no resto, ele necessariamente se aproxima da teoria, em razão dos conceitos que nele aparecem, trazendo de fora não só seus significados, mas também seus referenciais teóricos”. Para Hazlitt, como vimos, a não identidade entre as ideias do crítico ensaísta e o material ao qual elas se aplicam impõe a este um esforço contínuo. Mas essa é somente uma das semelhanças entre arte e crítica. Pois, pode-se acrescentar que para esta, como vimos ao longo deste artigo, ao contrário do que é para a teoria, os conceitos e as ideias, quando não artisticamente entalhados nos tropos e nas figuras comuns a uma língua. jamais podem servir de "meios específicos", na expressão de Adorno, para comunicar ou expressar o objeto.
} 
reúne o múltiplo e o plasma na expressão singular. Algo semelhante faz o crítico e ensaísta, mas sem os instrumentos facilitadores da poesia: como ritmo e métrica deliberados. Em outras palavras, a criação no ensaio crítico é de natureza mais árdua e sublime, próxima àquela que ocorre na escultura ou nas artes da fundição do ferro e do barro - "trabalho viril, agressivo e que se impõe com gesto brusco” -, nas palavras de Gilda de Melo e Souza (2005, p. 140), e que bem poderiam ser de Hazlitt. ${ }^{42}$

\section{REFERÊNCIAS}

ABRAMS, M. H. O espelho e a lâmpada: teoria romântica e tradição crítica. Trad. Alzira Vieira Allegro. São Paulo: Editora Unesp, 2010.

ADDISON, Joseph. Ensaio n. 40. V. 1. In: ADDISON, Joseph et al. The Spectator. 4 V. London: Everyman's Library, 1966a, pp. 120-123.

ADDISON, Joseph. Ensaio n. 285. V. 2. In: ADDISON, Joseph et al. The Spectator. 4 V. London: Everyman's Library, 1966b, pp. 348-353.

ADDISON, Joseph et al. The Spectator. 4 V. London: Everyman's Library, 1966.

ADDISON, Joseph; STELLE, Richard. Selection from the Tatler and the Spectator. London: Penguin Books, 1982.

ADORNO, Theodor. Notas de literatura I. Trad. Jorge de Almeida. São Paulo: Duas Cidades / Editora 34, 2008.

ARISTÓTELES. Ética a Nicômaco e poética. Trad. Eudouro de Souza. São Paulo: Nova Cultural, 1987.

ARRIGUCCI JR., Davi. Coração partido: uma análise da poesia reflexiva de Drummond. São Paulo: Cosac e Naify, 2002.

AUERBACH, Erich. Ensaios de literatura ocidental: filologia e crítica. Trad. Samuel Titan Jr. São Paulo: Duas Cidades / Editora 34, 2007.

BAUDELAIRE, Charles. As flores do mal. Trad. Ivan Junqueira. São Paulo: Editora Nova Fronteira, 2012.

\footnotetext{
${ }^{42}$ Na seguinte passagem de The Plain Speaker, o poeta se mostra insuficientemente viril no manejo com a matéria prosaica: "Nor does he [the poet] collect his strength to strike fire from the flint by the sharpness of collision, by the eagerness of his blow" [Tampouco ele [o poeta] reúne forças, com a avidez de seus golpes, para atear fogo do sílex] (HAZLITT, 1998d, p. 7).
} 
BLOOM, Harold. William Hazlitt. In: Essayists and Prophets. Philadelphia: Chelsea House Publishers, 2005, pp. 69-81.

BORGES, Jorge Luis. Curso de literatura inglesa. Trad. Eduardo Brandão. São Paulo: Martins Fontes, 2006.

BOSWELL, James. Life of Johnson. Oxford: Oxford University Press, 2008.

BOWRA, Cecil Maurice. The Romantic Imagination. Cambridge: Harvard University Press, 1949.

BROMWICH, David. Hazlitt: The Mind of a Critic. New Haven: Yale University Press, 1999.

BURKE, Edmund. Reflections on the Revolution in France. Oxford: Oxford University Press, 1999.

BURKE, Edmund. Uma investigação filosófica sobre a origem de nossas ideias do sublime e do belo. Trad. Enid Abreu. Campinas: Editora Unicamp, 2013.

CANDIDO, Antonio. Tese e síntese. Rio de Janeiro: Ouro sobre Azul, 2006.

CARPEAUX, Otto Maria. História da literatura ocidental. V. VII, "Romantismo". Rio de Janeiro: Ed. Cruzeiro, 1966.

COLERIDGE, Samuel Taylor. Passages from the Prose and Table Talk. London: Walter Scott, 19-?.

COLERIDGE, Samuel Taylor. Biographia Literaria or Biographical Sketches of my Literary Life and Opinions. London: Everyman's Library, 1971.

COLERIDGE, Samuel Taylor. The Collected Works of Samuel Coleridge: Lectures 1808-1819 on Literature I. Princeton: Princeton University Press, 1987a.

COLERIDGE, Samuel Taylor. The Collected Works of Samuel Coleridge: Lectures 1808-1819 on Literature II. Princeton: Princeton University Press, 1987b.

COLERIDGE, Samuel Taylor. A balada do velho marinheiro. Trad. Alípio Correia Franco Neto. São Paulo: Ateliê Editorial, 2005.

ELIOT, T. S. Selected Essays 1917-1932. New York: Harcourt, Brace and Company, 1932.

FOUCAULT, Michel. Le mots et le choses: une archéologie des sciences humaines. Paris: Gallimard, 1966.

FREYRE, Gilberto. Alhos E bugalhos: ensaios sobre temas contraditórios: de Joyce à cachaça; de José Lins do Rego ao cartão-postal. Rio de Janeiro: Nova Fronteira, 1978.

GILMARTIN, Kevin. William Hazlitt: Political Essayist. Oxford: Oxford University Press, 2015. 
Remate de Males, Campinas-SP, v. 37, n. 2, p. 763-784, jul./dez. 2017 - 783

HAZLITT, William. The Selected Writings of William Hazlitt; Volume 2: The Round Table; Lectures on the English Poets. London: Pickering \& Chatto, 1998a.

HAZLITT, William. The Selected Writings of William Hazlitt; Volume 5: Lectures on the English Comic Writers; Lectures on the Dramatic Literature of the Age of Elizabeth; A Letter to William Gifford, Esq. London: Pickering \& Chatto, 1998b.

HAZLITT, William. The Selected Writings of William Hazlitt; Volume 6: Table Talk. London: Pickering \& Chatto, 1998c.

HAZLITT, William. The Selected Writings of William Hazlitt; Volume 8: The Plain Speaker. London: Pickering \& Chatto, 1998d.

HAZLITT, William. The Selected Writings of William Hazlitt; Volume 9: Uncollected Essays. London: Pickering \& Chatto, 1998e.

HAZLITT, William. The Plain Speaker: The Key Essays. Oxford: Blackwell Publishers, $1998 f$.

HAZLITT, William. William Hazlitt on the Elgin Marbles. Organizado por Tom Paulin London: Hesperus Press Limited, 2008.

HAZLITT, William. Sobre a poesia em geral. Trad. Roberto Acízelo de Souza. In: SOUZA, Roberto Acízelo de (org.). Uma ideia moderna de literatura: textos seminais para os estudos literários (1688-1922). Chapecó: Argos Editora da Unochapecó, 2011.

HAZLITT, William. Sobre os ensaístas de periódico. Trad. Daniel Lago Monteiro. Serrote, São Paulo, Instituto Moreira Salles, n. 22, 2016, pp. 19-41.

HORÁCIO. A arte poética. Trad. Dante Tringali. São Paulo: Musa Editora, 1994.

HUME, David. A arte de escrever ensaios e outros ensaios (morais, políticos e literários). Trad. Márcio Suzuki e Pedro Pimenta. São Paulo: Iluminuras, 2011.

KEATS, John. Selected Letters of John Keats. Cambridge / Massachusetts: Harvard University Press, 2002.

LONGINO. Do sublime. Trad. Filomena Hirata. São Paulo: Martins Fontes, 1996.

MEE, Jon. Conversable Worlds: Literature, Contention, E Community 1762-1830. Oxford: Oxford University Press, 2013[2011].

MONK, Samuel. The Sublime: A Study of Critical Theories in XVIII-century England. Ann Arbor: University of Michigan Press, 1960.

MONTAINGE, Michel de. Os ensaios: Livro I. Trad. Rosemary Costhek Abílio. São Paulo: Martins Fontes, 2002. 
NOVALIS, Friedrich von Hardenberg. Pólen: fragmentos, diálogos, monólogo. Trad. Rubens Rodrigues Torres Filho. São Paulo: Iluminuras, 2009.

OZICK, Cynthia. Retrato do ensaio como corpo de mulher. Trad. Alexandre Barbosa de Souza. Serrote, São Paulo, Instituto Moreira Salles, n. 9, 2011, pp. 7-13.

PAES, José Paulo. Armazém literário. São Paulo: Companhia das Letras, 2008.

PAULIN, Tom. The Day-Star of Liberty: William Hazlitt's Radical Style. London: Faber and Faber, 1998.

PEREIRA, Lucia Miguel. Sobre os ensaístas ingleses. Serrote, São Paulo, Instituto Moreira Salles, n. 22, 2016, pp. 5-17.

QUINCEY, Thomas de. De Quincey as Critic. London / Boston: Routledge \& Kegan Paul, 1973.

SAINTE-BEUVE. Oeuvres I. Paris: Gallimard, 1949.

SARTRE, Jean-Paul. Que é a literatura? Trad. Carlos Felipe Moisés. Petrópolis: Vozes, 2013.

SOUZA, Gilda de Melo. A ideia e o figurado. São Paulo: Duas Cidades / Editora 34, 2005.

STAROBINSKI, Jean. É possível definir o ensaio? Trad. André Telles. Serrote, São Paulo, Instituto Moreira Salles, n. 10, 2012, pp. 43-61.

SULLIVAN, John Jeremiah. Essai, essay, ensaio. Trad. Alexandre Barbosa de Souza. Serrote, São Paulo, Instituto Moreira Salles, n. 19, 2015, pp. 131-144.

SUZUKI, Márcio. A forma e o sentimento do mundo: jogo, humor e arte de viver na filosofia do século XVIII. São Paulo: Editora 34, 2014.

WEISKEL, Thomas. O sublime romântico: estudos sobre a estrutura e psicologia da transcendência. Rio de Janeiro: Biblioteca Pierre Menard Imago, 1994.

WELLEK, René. História da crítica moderna II: o Romantismo. São Paulo: Editora Herder, 1967.

WIMSATT, William \& BROOKS, Cleanth. Crítica literária: breve história. Lisboa: Fundação Calouste Gulbenkian, 1971.

WORDSWORTH, Wordsworth. Lyrical Ballads. London: Methuen, 1963.

WU, Duncan. William Hazlitt: The First Modern Man. Oxford: Oxford University Press, 2008. 